\title{
Porous Carbon Grown by Chemical Vapor Deposition on Copper Substrates
}

\author{
D. Mendoza \\ Instituto de Investigaciones en Materiales, Universidad Nacional Autónoma de México, \\ México D. F., México \\ Email: doroteo@unam.mx
}

Received 26 June 2015; accepted 31 July 2015; published 3 August 2015

Copyright (C) 2015 by author and Scientific Research Publishing Inc.

This work is licensed under the Creative Commons Attribution International License (CC BY).

http://creativecommons.org/licenses/by/4.0/

c) (i) Open Access

\begin{abstract}
Amorphous porous carbon was synthesized by chemical vapor deposition on copper substrates. The average size of the pores is around 1.2 microns with some small pores decorating the big ones. Lamellar samples of this carbonaceous material can be separated from the copper support and may be useful as electrode due to its low electrical resistivity of the order of $0.4 \Omega \mathrm{cm}$.
\end{abstract}

\section{Keywords}

Porous Carbon, Graphene-Like Materials, Conductive Electrodes, Chemical Vapor Deposition

\section{Introduction}

The synthesis and study of porous carbons have attracted great attention due to their novel physical and chemical properties [1] [2] and for their possible applications, between others, for energy storage as a component in supercapacitors [3] or for their use in the purification of water [4]. Two of the main characteristics of porous carbons are the high aspect ratio of surface area to volume, and the existence of reactive sites, such as dangling bonds which make this material useful for many potential applications. In the last years, graphene, a novel two dimensional carbon nanostructure, has received much attention ought to its physical properties, such as its high electrical mobility, and for its potential applications in electronic devices [5]. A usual technique to synthesize graphene is by thermal decomposition of hydrocarbons (chemical vapor deposition, CVD) on copper surfaces [6]. In the search to find experimental conditions for the synthesis of monolayer and multilayer graphene by the CVD technique [7]-[10], we found the existence of a carbonaceous porous material. The main purpose of the present letter is the report of the finding and structural characteristics of porous carbon obtained by the CVD technique.

How to cite this paper: Mendoza, D. (2015) Porous Carbon Grown by Chemical Vapor Deposition on Copper Substrates. Journal of Materials Science and Chemical Engineering, 3, 16-20. http://dx.doi.org/10.4236/msce.2015.38003 


\section{Experimental Details}

Copper foils ( $\sim 5 \mathrm{~mm} \times 5 \mathrm{~mm}, 100$ microns of thickness) inside fused quartz crucible were loaded on the center of a tubular furnace, in some runs fused quartz plates were also put together with copper substrates. The substrates were heated to $1000^{\circ} \mathrm{C}$ in argon ambient, at this temperature argon was cut off and replaced by pure methane (flux $=7 \mathrm{sccm}$ ) at ambient pressure during 15 minutes. After this period methane was cut off and pure argon was admitted again and immediately the furnace was turned off for cooling naturally to room temperature. In the case of fused quartz, the carbonaceous material is a lustrous continuous film well adhered to the substrate, but in the case of copper substrate a grayish layer poor adhered to the foil is obtained. It is observed that only the carbonaceous material covering the cooper foils has porous morphology.

Optical (Iroscope MO-64), scanning (SEM, Jeol 7600F), transmission (TEM, Jeol JEM-1200EX) electron microscopes, and X-ray diffraction (Bruker AXS, D8 ADVANCE) were used for structural characterization. For TEM studies, a small piece of the porous carbonaceous layer was sonicated for some minutes in ethanol and drops of the obtained suspension were put on copper grids. For electrical measurements the copper foil was dissolved in a ferric nitrate solution.

\section{Results and Discussion}

In Figures 1(a)-(c) SEM images of the material synthesized on copper foil are presented. After cutting the copper foil for a SEM sample, the carbonaceous material delaminated easily as is observed in Figure 1(a). An overview of the porous carbon mainly shows two levels of porous average size: 1.2 microns (Figure 1 (a)) and $195 \mathrm{~nm}$ (Figure 1(b)); the existence of the small porous inside the great one is clearly observed in Figure 1(c). In Figure 1(d) an image of the same sample observed with an optical microscope is shown.

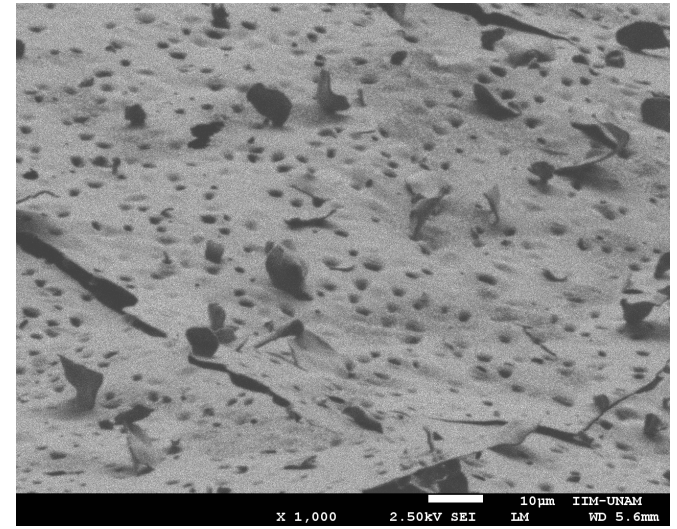

(a)

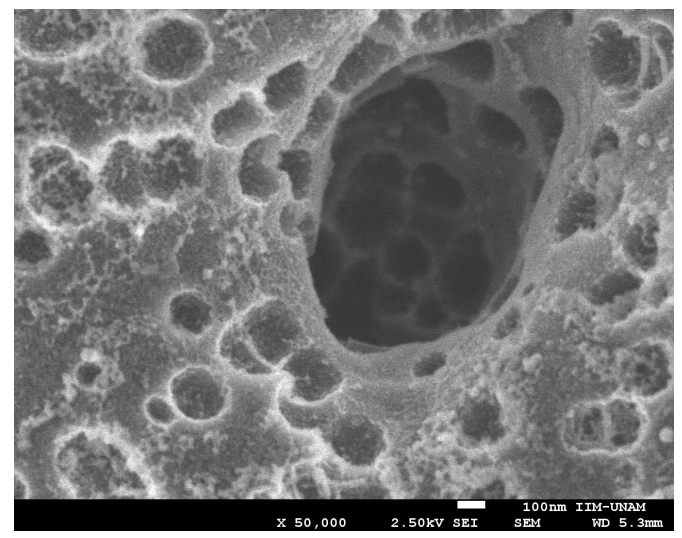

(c)

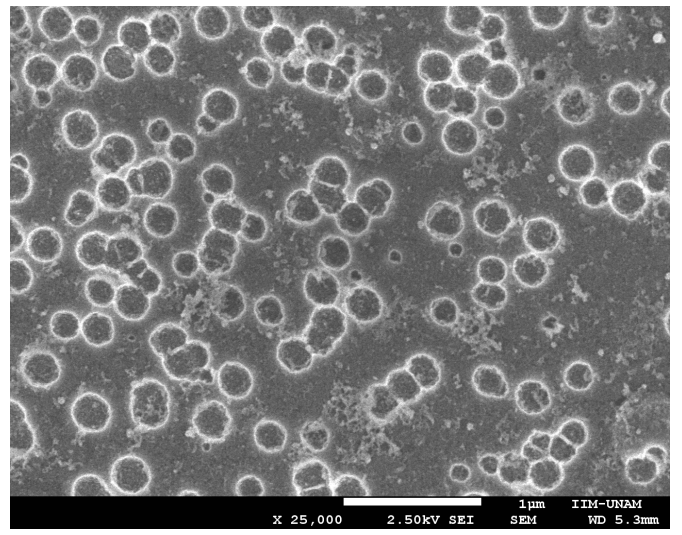

(b)

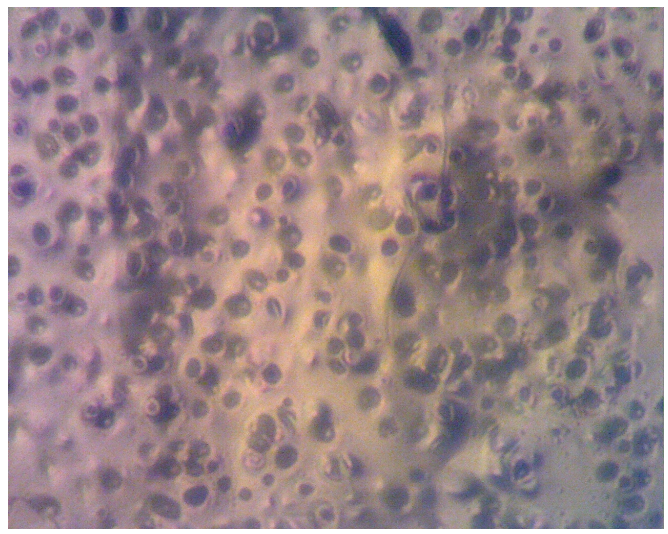

(d)

Figure 1. Scanning electron micrographs of the porous carbon with different scale bars (a) 100 microns; (b) 1 micron; and (c) $100 \mathrm{~nm}$; (d) is an optical image taken with total amplification of 400. 
Figure 2(a) shows X-ray diffractograms of the porous as well as the continuous film. It is noted that both carbonaceous materials are amorphous, showing a broad peak centered around $2 \theta=25.6^{\circ}$, indicating a high degree of disorder in the phase, similar to carbonaceous material deposited on other substrates [11]. Amorphous phase of the porous material is corroborated by electron diffraction, as is shown in Figure 2(b), where no spots related to any crystalline phase are observed.

It is known that the carbonaceous material obtained by the CVD method is mainly amorphous up to $1700^{\circ} \mathrm{C}$ and some crystalline structure is observed above $2000^{\circ} \mathrm{C}$, but the kind of substrate can modify the structure of the material. For example, deposited material on Fe and Ni substrates has graphitic structure at temperatures as low as $1000^{\circ} \mathrm{C}$, in contrast amorphous carbon on Cu substrate is obtained at the same temperature, even if methane is 30\% diluted in argon [12]. Recent studies on CVD technique using methane as the carbon precursor and copper as the substrate have clearly established that crystalline structures (graphene and few layer graphene) are obtained at $1000^{\circ} \mathrm{C}$ only if methane is highly diluted in other gas (argon and/or hydrogen) or in vacuum conditions [6] [13] [14]. The result obtained in the present work is consistent with that reported in the literature because, using pure methane at atmospheric pressure and $1000^{\circ} \mathrm{C}$, the obtained carbonaceous material is amorphous. In a more recent experiments in our laboratory we have synthesized few layer graphene on copper substrates using highly diluted (1\%) methane in argon at atmospheric pressure (results not presented).

We propose the following explanation for the formation of porous structure of the amorphous carbon deposited on copper. The $\mathrm{Cu}$ and fused quartz substrates are in the same conditions of temperature and flux of methane because they are near each other at the interior of the furnace. Methane molecules are thermally decomposed on the surface of the substrate and hydrogen is liberated; in this process heat is absorbed from the substrate. Being copper a good heat conductor, we believe that the heat exchange between copper and the surrounding methane is an efficient process, and due to the high concentration of molecules (atmospheric pressure), high quantities of hydrogen is produced in the decomposition of methane. The hydrogen is liberated to the flow and breaks the growing carbonaceous film producing holes, which finally gives the porous morphology. On the fused quartz substrate the heat exchange is less effective than in copper, hence thermal decomposition of methane is slower producing less hydrogen, and no effect on the morphological structure of the growing carbonaceous film is expected.

Respect to the electrical properties of the synthesized porous carbon, its electrical resistance above room temperature was measured. For these measurements the copper foil was dissolved, the resultant lamella was washed several times with deionized water and captured on a glass slide. Once the carbonaceous lamella was dried, two parallel electrical contacts were carefully put using silver paste on the glass substrate. Prior to measurements, the sample was annealed in vacuum $\left(\sim 10^{-4} \mathrm{Torr}\right)$ at $120^{\circ} \mathrm{C}$ during 15 minutes. In Figure 3(a) the current against voltage curve is presented, where an ohmic behavior is clearly observed, and in Figure 3(b) re-

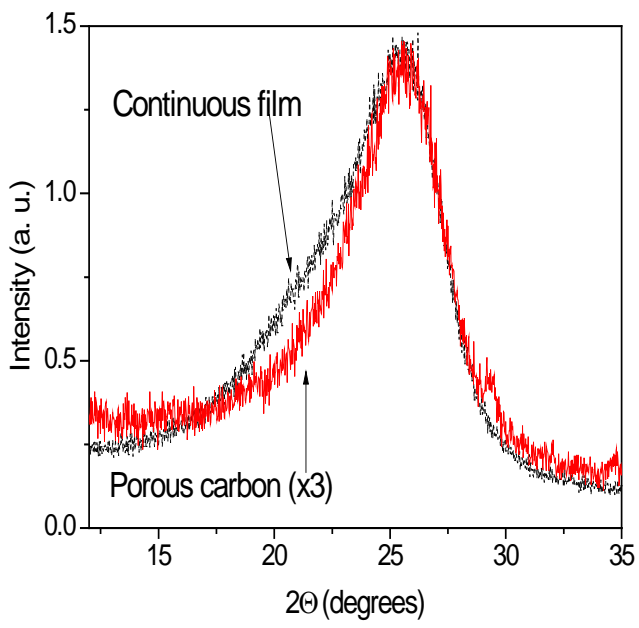

(a)

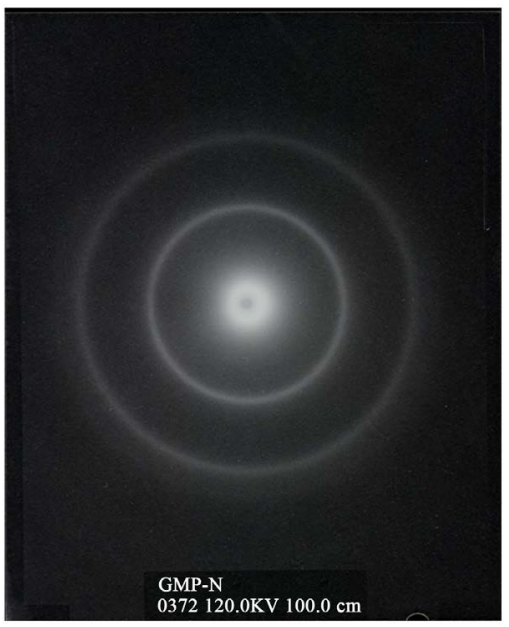

(b)

Figure 2. (a) X-ray diffractograms of the carbonaceous material deposited on fused quartz (continuous film) and porous carbon; (b) Electron diffraction pattern of the porous material, showing the typical annular form of an amorphous material. 


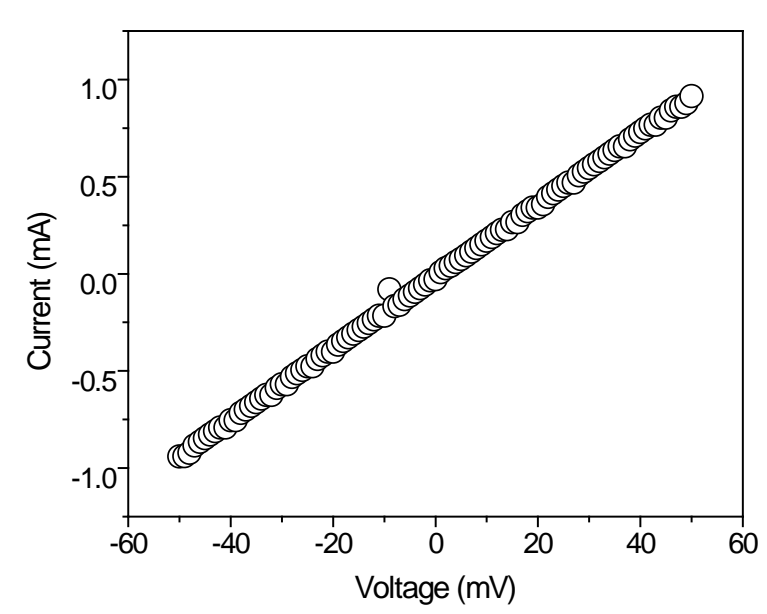

(a)

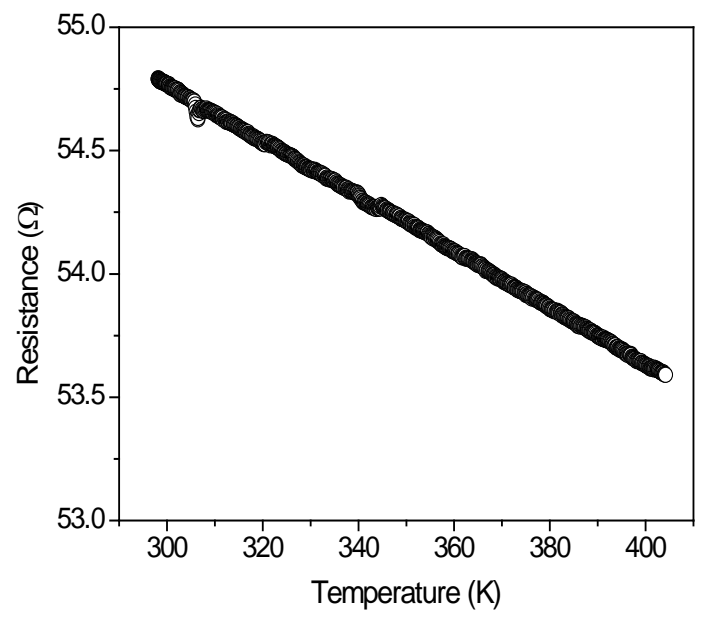

(b)

Figure 3. Electrical characteristics of porous carbon. (a) Current against voltage showing an ohmic behavior; (b) Electrical resistance as a function of temperature where a linear dependence with a slope of $-0.011 \Omega / \mathrm{K}$ is observed.

sistance (R) against temperature (T) is plotted. It is observed that the resistance of the porous carbon material slightly decreases almost linearly as the temperature increases. Using a profilometer we made an estimation of the thickness of the lamella of $\sim 75$ microns, which gives a resistivity of $\sim 0.4 \Omega \mathrm{cm}$. For comparison purposes, the resistivity of the continuous film deposited on fused quartz substrate is $\sim 1.8 \times 10^{-3} \Omega \mathrm{cm}$, the difference between these two values may be due to the discontinuous morphology of the porous material. It should be noted that even taking the greater value for the resistivity of $0.4 \Omega \mathrm{cm}$ for our porous carbon, it is comparable with that reported for graphene foams [15].

\section{Conclusion}

We have reported the synthesis of porous carbon by the thermal decomposition of pure methane at $1000^{\circ} \mathrm{C}$ on copper substrates. At this high concentration of hydrocarbon, copper does not work as a catalyst for the growth of graphene or multilayer graphene, instead, amorphous carbon grows. The important characteristics of the obtained material are: 1) porous morphology, 2) low electrical resistivity, and 3) due to the lamellar form, its size can be scaled and its geometry can be controlled using the appropriate form of the copper foil substrate. We believe that this material may be useful as electrode for supercapacitor applications using an ionic liquid absorbed within their pores.

\section{Acknowledgements}

I thank A. Tejeda (X-ray), O. Novelo (SEM), C. Flores (TEM), and R. Reyes (electronic instrumentation) of IIM-UNAM for their valuable assistance. I also thank Dr. S. Muhl (IIM-UNAM) for facilitate us the use of the profilometer.

\section{References}

[1] White, R.J., Budarin, V., Luque, R., Clark, J.H. and Macquarri, D.J. (2009) Tuneable Porous Carbonaceous Materials from Renewable Resources. Chemical Society Reviews, 38, 3401-3418. http://dx.doi.org/10.1039/b822668g

[2] Shen, W.Z. and Fan, W. (2013) Nitrogen-Containing Porous Carbon: Synthesis and Application. Journal of Materials Chemistry A, 1, 999-1013. http://dx.doi.org/10.1039/C2TA00028H

[3] Kim, T.Y., Jung, G., Yoo, S., Yoo, K.S., Suh, K.S. and Ruoff, R.S. (2013) Activated Graphene-Based Carbons as Supercapacitor Electrodes with Macro- and Mesopores. ACS Nano, 7, 6899-6905. http://dx.doi.org/10.1021/nn402077v

[4] Tanugi, D.C. and Grossman, J.C. (2012) Water Desalination across Nanoporous Graphene. Nano Letters, 12, 36023608. http://dx.doi.org/10.1021/nl3012853

[5] Geim, A.K. and Novoselov, K.S. (2007) The Rise of Graphene. Nature Materials, 6, 183-191.

http://dx.doi.org/10.1038/nmat1849 
[6] Li, X., Cai, W., An, J., Kim, S., Nah, J., Yang, D., et al. (2009) Large-Area Synthesis of High-Quality and Uniform Graphene Films on Copper Foils. Science, 324, 1312-1314. http://dx.doi.org/10.1126/science.1171245

[7] Bautista-Flores, C., Sato-Berrú, R.Y. and Mendoza, D. (2014) Charge Transfer in the Fullerene C60-Few Layer Graphene System and the Existence of Negative Photoconductivity. Applied Physics Letters, 105, Article ID: 191116. http://dx.doi.org/10.1063/1.4902055

[8] Benítez, J.L. and Mendoza, D. (2013) Modulation of the Optical Transmittance in Multilayer Graphene by an Electrical Signal. Applied Physics Letters, 103, Article ID: 083116. http://dx.doi.org/10.1063/1.4819466

[9] Mendoza, D. (2012) Electrical Conductivity of Collapsed Multilayer Graphene Tubes. World Journal of Nano Science and Engineering, 2, 53-57. http://dx.doi.org/10.4236/wjnse.2012.22009

[10] Bautista, C. and Mendoza, D. (2011) Multilayer Graphene Synthesized by CVD Using Hexane as the Carbon Precursor. World Journal of Condensed Matter Physics, 1, 157-160. http://dx.doi.org/10.4236/wjcmp.2011.14023

[11] Mendoza, D., López, S., Granados, S., Morales, F. and Escudero, R. (1997) Incorporation of Selenium into Carbon Films by Chemical Vapor Deposition. Synthetic Metals, 89, 71-72. http://dx.doi.org/10.1016/S0379-6779(97)81195-2

[12] Li, W.N., Ding, Y.S., Suib, S.L., Di Carlo, J.F. and Galasso, F.J. (2005) Controlling the Growth of CVD Carbon from Methane on Transition Metal Substrates. Surface and Coatings Technology, 190, 366-371. http://dx.doi.org/10.1016/j.surfcoat.2004.06.026

[13] Bharripudi, S., Jia, X., Dresselhaus, M.S. and Kong, J. (2010) Role of Kinetic Factors in Chemical Vapor Deposition Synthesis of Uniform Large Area Graphene Using Copper Catalyst. Nano Letters, 10, 4128-4133. http://dx.doi.org/10.1021/nl102355e

[14] Lewis, A.M., Derby, B. and Kinloch, I.A. (2013) Influence of Gas Phase Equilibria on the Chemical Vapor Deposition of Graphene. ACS Nano, 7, 3104-3117. http://dx.doi.org/10.1021/nn305223y

[15] Chen, Z., Ren, W., Gao, L., Liu, B., Pei, S. and Cheng, H. (2011) Three-Dimensional Flexible and Conductive Interconnected Graphene Networks Grown by Chemical Vapor Deposition. Nature Materials, 10, 424-428. http://dx.doi.org/10.1038/nmat3001 